\title{
Инфракрасная термография как ведущая информационная технология сегодняшнего дня
}

\author{
Б.Г. Вайнер \\ Институт физики полупроводников им. А.В. Ржанова СО РАН, \\ Новосибирский государственный университет \\ *E-mail: boris-kvant@mail.ru
}

DOI:10.31868/RFL2018.230-231

Ход развития современной экспериментальной науки отличается тем, что в уже, казалось бы, до пределов заполненный эшелон всевозможных применяемых здесь технических средств и принципов измерений продолжают непрерывно вливаться всё новые и новые инструменты физических исследований. Такая "парадоксальная" тенденция имеет простое объяснение: исключительно быстрый технический прогресс, происходящий в области автоматизации эксперимента и его программно-компьютерного обеспечения, служит, по сути, неисчерпаемым источником, порождающим новые высокопроизводительные приборы и системы, а также свежие методы и подходы в экспериментальной физике.

Инфракрасная (ИК) термография, традиционно называемая "тепловидением", принадлежит к числу вышеупомянутых современных измерительных средств физического эксперимента. Если раньше этот метод позволял лишь визуализировать тепловое излучение тел, что само по себе уже не мало, то в настоящее время он превратился в мощный высокоточный (чувствительность порядка сотой доли градуса) быстродействующий (частота кадров порядка 100 и более в секунду) количественный инструмент исследований [1], информативность которого в своей нише не достижима никакими другими методами измерений в силу ее уникальности.

В обоснование сказанного можно привести примеры термограмм (поверхностных температурных полей), представленных на рис. 1. Ясно, что лишь с помощью тепловидения возможно обнаружить особенности температурных карт изображенных поверхностей.

Современные матричные тепловизионные системы и их программное обеспечение превратили обсуждаемый метод из качественного в количественный (за рубежом это принято называть quantitative infrared thermography - QIRT). При этом в последние годы повышенный интерес стали проявлять к динамическим (скоростным) тепловизионным исследованиям природных процессов [2, 3].

a

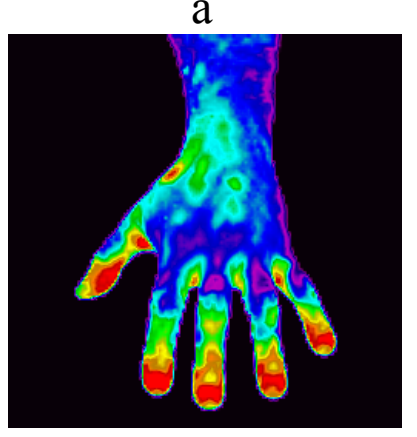

6

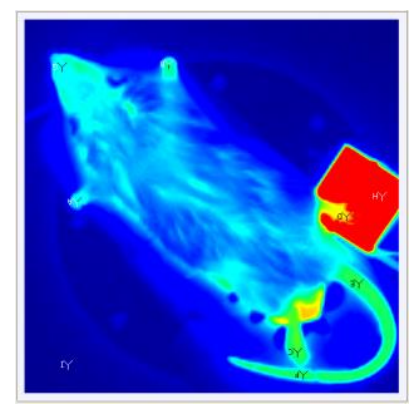

B

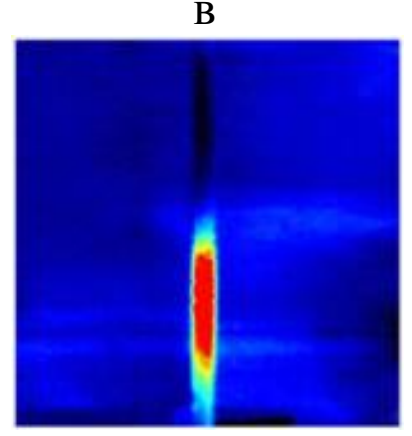

Рис.1. а) Термограмма тыльной стороны кисти человека; б) экспериментальное животное (крыса), задняя лапка которого нагревается модулем Пельтье;

в) тепловая волна в слое цеолита. 


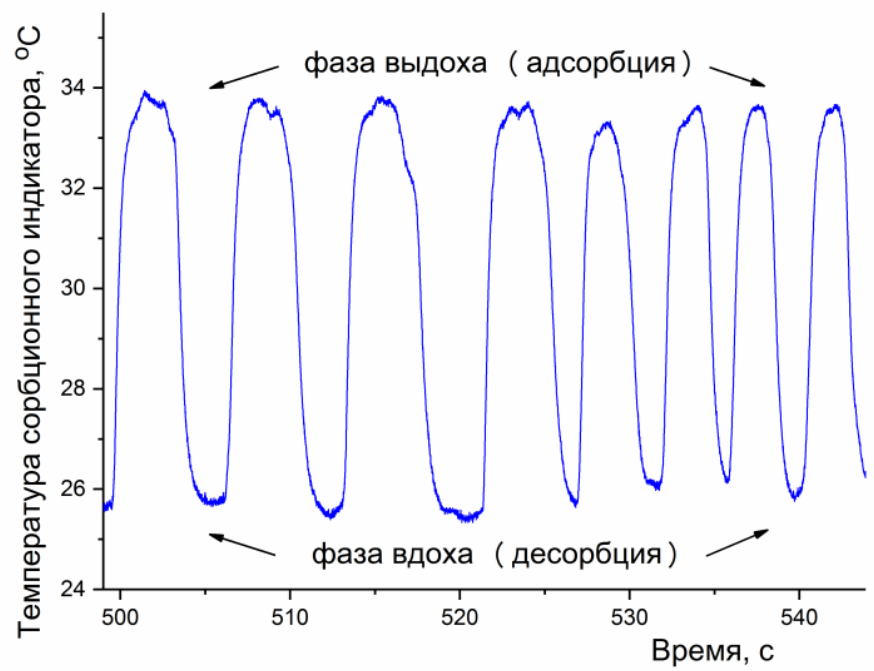

Рис.2. Вариация температуры поверхности сорбционного индикатора, описанного в [2], вызванная дыханием человека и измеренная с частотой 100 кадров в секунду с применением тепловизионной камеры нового поколения.

Иллюстрация динамического подхода в тепловидении представлена на рис. 2. Из приведенного графика видно, что ИК термография дает, к примеру, возможность регистрировать тончайшие нюансы в динамике дыхания людей и животных. В частности, из рис. 2 следует, что в определенный момент времени (около 525 секунд от начала отсчета) частота дыхания испытуемого существенно изменяется (увеличивается), причем в показанном случае это обусловлено сокращением паузы как в фазе вдоха, так и выдоха.

В настоящем докладе разносторонне представлены наиболее важные направления современной ИК термографии при ее использовании в научнотехнических, биомедицинских и народно-хозяйственных областях.

Работа выполнена при финансовой поддержке РФФИ и Правительства Новосибирской области, грант № 18-44-540040.

\section{Литература}

[1] B.G. Vainer., J. Phys. D: Appl. Phys. 41, 065102 (12 pp) (2008)

[2] B.G. Vainer., Ann. Biomed. Eng. 46, 960-971 (2018)

[3] B.G. Vainer, S.S. Fast, P.A. Pyrjaev, B.L. Moroz. // In: XXI Int. Conf. on Chem. Thermodyn. in Russia (RCCT-2017) (June 26-30, 2017, Novosibirsk, Russia): Abstracts // Novosibirsk: NIIC SB RAS, 318 (2017) 